\title{
Wyrtki Jets: Role of intraseasonal forcing
}

\author{
S Prerna ${ }^{1, *}$, Abhisek ChatterJee ${ }^{1}$, A MukherJee ${ }^{1}$, M Ravichandran $^{2}$ \\ and S S C SHENOI ${ }^{1}$ \\ ${ }^{1}$ Indian National Centre for Ocean Information Services, Hyderabad 500 090, India. \\ ${ }^{2}$ National Centre for Antarctic and Ocean Research, Goa 403 804, India. \\ *Corresponding author.e-mail: prerna.s@incois.gov.in
}

MS received 23 January 2018; revised 16 April 2018; accepted 17 April 2018; published online 4 January 2019

Direct current measurements observed from the acoustic Doppler current profilers in the equatorial Indian Ocean (EIO) and solutions from an ocean general circulation model are investigated to understand the dynamics of the Wyrtki jet. These jets are usually described as semiannual direct wind forced zonal currents along the central and eastern EIO. We show that both, spring and fall, Wyrtki jets show predominant semiannual spectral peaks, but significant intraseasonal energy is evident during spring in the central and eastern EIO. We find that for the semiannual band, there is a strong spectral coherence between the overlying winds and the currents in the central EIO, but no coherency is observed in the eastern part of the EIO. Moreover, for the intraseasonal band, strong coherency between the winds and currents is evident. During spring, intraseasonal currents induced by the Madden-Julian oscillation (MJO) superimpose constructively with semiannual currents and thus intensify the strength of the spring Wyrtki jet. Also, the atmospheric intraseasonal variability accounts for the interannual variabilities observed in spring Wyrtki jets.

Keywords. Indian Ocean; equatorial dynamics; MJO; zonal currents.

\section{Introduction}

The equatorial Indian Ocean (EIO), unlike the Pacific and Atlantic Oceans, is characterised by strong eastward surface currents, forced directly by the equatorial westerlies, occur during the intermonsoons (April-May and November), known as Wyrtki jets (WJs) (Wyrtki 1973). WJs advect warm surface water eastward and thereby raise (lower) the sea level and deepen (raise) the thermocline in the eastern (western) EIO (Rao et al. 1989; Schott and McCreary 2001). It is known that this zonal redistribution of heat, salt and water mass plays a very important role in the regional and global climate system (Murtugudde and Busalacchi 1999; Vinayachandran et al. 1999; Chatterjee et al. 2017). Considering the significance of WJs for the sustaining of east-west contrast at seasonal to interannual time scales (Reppin et al. 1999; McPhaden et al. 2015), much attention has been paid in many studies during the recent decades for quantifying its variability and for understanding its dynamics (McCreary et al. 1993; Han et al. 1999; Yuan and Han 2006; Nagura and McPhaden 2008, 2010a, b). 
WJs exhibit strong interannual variability caused by the anomalous wind forcing along the equator. The equatorial zonal wind and the monsoon current regions respond strongly to the El Niño Southern Oscillation (ENSO) phenomena with weaker (stronger) winds during El Niño (La Niña) (Alexander et al. 2002). Besides, the existence of Indian Ocean dipole zonal mode (IODZM) also causes variations in the magnitude of the fall jet over interannual time scales (Vinayachandran et al. 1999, 2007; Murtugudde et al. 2000; Gnanaseelan et al. 2012). In one such study, Joseph et al. (2012) proposed a weakening of spring WJs during 20062011 apparently associated with La Niña events or IODZM years preceding La Niña years, when the location of the latitude of zero zonal winds is close to the equator.

In addition to these low-frequency variabilities, significant wind forced intraseasonal fluctuations (of 30-90-day period band) in the zonal equatorial current are also reported by many (see, e.g., McPhaden 1982; Han et al. 2001; Senan et al. 2003; Sengupta et al. 2007). Recent advances in ocean observations, particularly through the Research Moored Array for African-Asian-Australian Monsoon Analysis and Prediction (RAMA) program (McPhaden et al. 2009) along with other in situ and satellite observations have led to fresh research in describing intraseasonal variability along the EIO (Masumoto et al. 2005; Nagura and McPhaden 2008, 2012; David et al. 2011; Iskandar and McPhaden 2011; Chatterjee et al. 2013).

Since most of the studies on WJ dynamics have focused on time scales at and longer than the semiannual periods, the shorter time scale variability of the equatorial jets in the warm water region of the eastern EIO has remained as an unsolved issue. Recently, Deshpande et al. (2017) showed the role of intraseasonal variability in the interannual variation of spring WJ. Further, they also hinted about possible influence of Madden-Julian oscillation (MJO) in driving the WJ along the equator. During November 2011, under the dynamics of MJO experiment, Moum et al. (2014) noticed that MJO wind bursts along the eastern EIO can considerably strengthen the magnitude of fall WJ currents. Furthermore, it has been shown that tropical cyclones over the Bay of Bengal also influence the magnitude of fall WJs (Sreenivas et al. 2012). Given the evidence of strong intraseasonal cycle in the EIO, in the present study, we intend to revisit the issue of the variability of WJs in the intraseasonal to interannual periods. Note here that while
Senan et al. (2003) have shown strong intraseasonal variability of zonal equatorial current over the Indian Ocean, they mainly focused on discussing the strong eastward intraseasonal currents that occurred during the Indian summer monsoon seasons and termed them as 'monsoon jets'. Here, we primarily focused on examining how 'intraseasonal currents' driven by equatorial intraseasonal winds affect the spring and fall WJs. Moreover, as MJOs account for most of the observed intraseasonal variability in the tropical Indian Ocean, particularly during November-May, which is the active phase of MJO in the Indian Ocean (Lau and Wu 2010), in this study, we try to understand the influence of MJOs on the strong equatorial zonal currents of the Indian Ocean. Specifically, we try to answer the following questions: How intraseasonal wind forcing influence the WJs? and how does this relate to its observed interannual variability?

In this paper, we mainly rely on in situ data from the equatorial acoustic Doppler current profilers (ADCPs) from RAMA program in combination with various other in situ and satellite data sets and a suite of solutions from an ocean general circulation model. The rest of the paper is organised as follows. Section 2 details the methodology adopted in this study. Section 3 describes the observed variability of WJs and validates our control run simulation. The relative importance of intraseasonal and semiannual winds in the WJs dynamics is discussed in section 4. Finally, in section 6 , we conclude and summarise our results.

\section{Methodology}

Here, we discuss our methodology to address the problem, describe the observed data set, model set-up, experiments and analysis techniques being used. A detail list of data sets used in this study is provided in table 1 .

\subsection{Observations}

Daily time series of subsurface current data obtained from the RAMA ADCP buoys, located at the $80.5^{\circ} \mathrm{E}$ and $90^{\circ} \mathrm{E}$ along the equator (figure 1 ), are used for this study. The ADCP at $80.5^{\circ} \mathrm{E}$ was deployed in October 2004 and has a data record till August 2012 with a gap of about a year during October 2008 to August 2009 (see table 1). At $90^{\circ} \mathrm{E}$, the $\mathrm{ADCP}$ provides a longer record starting from November 2000 to June 2012 with a gap 
Table 1. Details of the data sets used in the present study.

\begin{tabular}{lll}
\hline Data set & Frequency & Source \\
\hline ADCP $\left(0^{\circ}, 90^{\circ} \mathrm{E}\right)$ & Daily & RAMA \\
ADCP $\left(0^{\circ}, 80.5^{\circ} \mathrm{E}\right)$ & Daily & RAMA \\
OLR & Daily & NOAA/CDC \\
RMM index & Daily & Bureau of Meteorology, Australia \\
Tropflux wind stress & Daily & INCOIS \\
Short-wave radiation & Daily & Kalnay et al. $(1996)$ \\
Long-wave radiation & Daily & Kalnay et al. $(1996)$ \\
Surface air pressure & Daily & Kalnay et al. $(1996)$ \\
2 m air temperature & Daily & Kalnay et al. $(1996)$ \\
Specific humidity & Daily & Kalnay et al. $(1996)$ \\
Precipitation & Daily & TRMM \\
River runoff & Monthly climatology & Vörösmarty et al. (1996) and Papa et al. (2010) \\
Chl & Monthly climatology & SeaWifs (http://oceancolor.gsfc.nasa.gov/cgi/level3.pl)
\end{tabular}
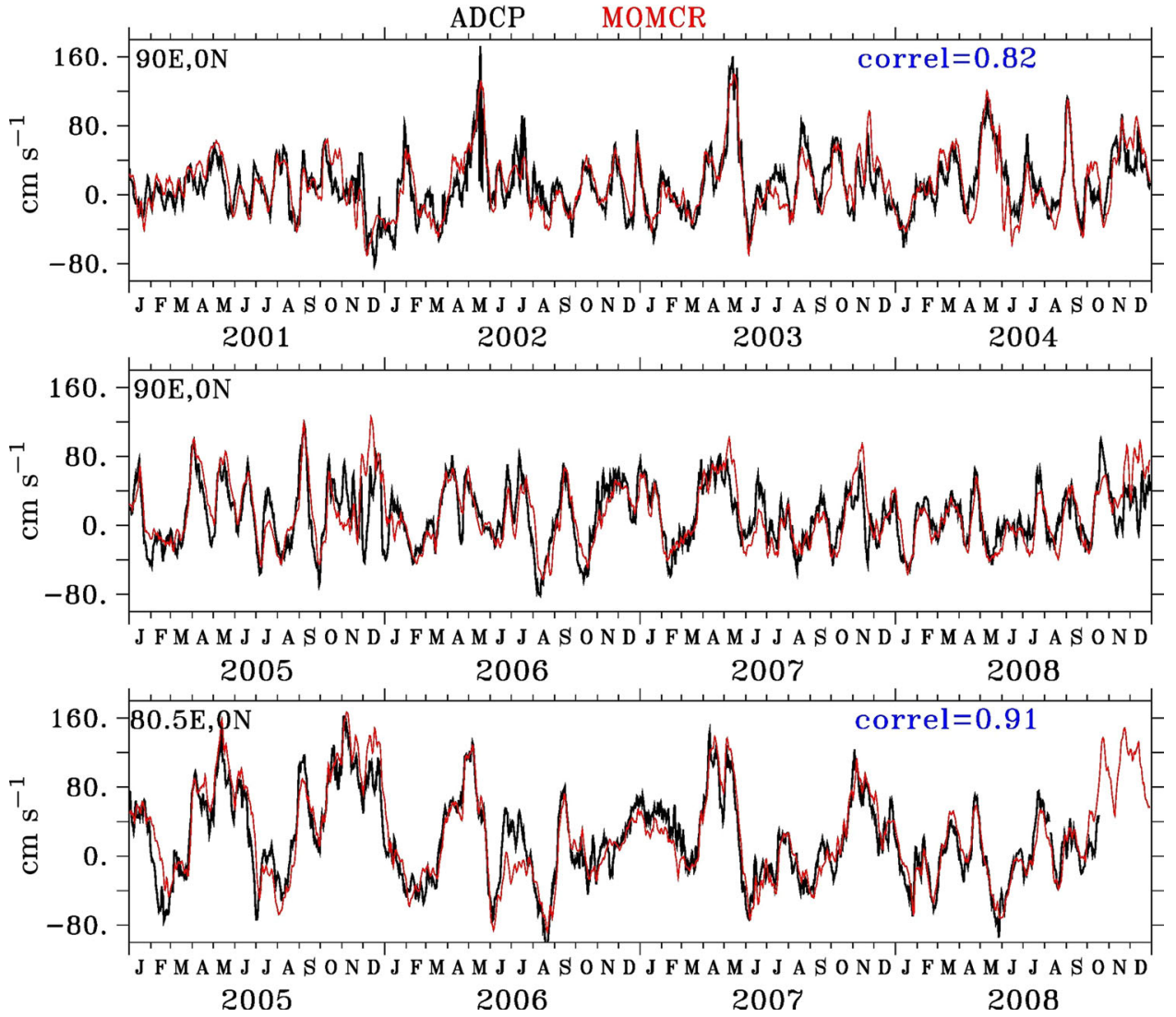

Figure 1. Comparison of near surface $(40 \mathrm{~m})$ zonal current observed at the $90^{\circ} \mathrm{E}$ (top and middle panels) and $80.5^{\circ} \mathrm{E}(\mathrm{bottom}$ panel) equatorial ADCP mooring with the MOMCR. Model performs reasonably well in reproducing observed variability in the EIO. The correlation between the observation and model simulation at both the locations is above $99 \%$ significance level. Note here that the strength of the WJs are maximum during spring of 2002 and 2003, whereas it is weakest during 2006-2008.

of about 8 months during March-November 2009 . We excluded the data from the upper $40 \mathrm{~m}$ of the water column for both the ADCPs as they might have been contaminated by signals reflected from the surface. Also, small gaps less than 10 days are linearly interpolated for the time-series analysis.
In order to understand the influence of MJOs on the equatorial jets, we obtained the daily averaged outgoing long-wave radiation (OLR) data with a horizontal resolution of $2.5^{\circ}$ from the National Oceanic and Atmospheric Administration's Climate Diagnostic Center (NOAA/CDC). 
In addition, the real-time multivariate MJO (RMM) index, which is used to monitor and predict the climate and weather variations related to the tropical MJO activities, is obtained from the Australian Government Bureau of Meteorology. The RMM index represents the phase and magnitude of MJO activity and is calculated using the first two empirical orthogonal functions of the combined fields of near-equatorially averaged $850 \mathrm{hPa}$ zonal wind, $200 \mathrm{hPa}$ zonal wind and satellite observed OLR data and are available in near real time about $12 \mathrm{~h}$ after the end of each Greenwich day (i.e., at about 1200 UTC).

In order to understand the dynamical forcing of the equatorial jets, we use daily averaged surface wind derived from TropFlux with $1^{\circ}$ resolution available from the Indian National Center for Ocean Information Services (INCOIS) (Kumar et al. 2013).

\subsection{Ocean model}

An Indian Ocean model based on modular ocean model (MOM4p1) has been used to decipher the role of intraseasonal/semiannual wind forcing on WJs. The model set-up is described earlier in many papers (Chatterjee et al. 2013; Shankar et al. 2016). Model domain spans the Indian Ocean from $30^{\circ} \mathrm{E}$ to $120^{\circ} \mathrm{E}$ and $30^{\circ} \mathrm{S}$ to $30^{\circ} \mathrm{N}$ with uniform horizontal resolution of $0.25^{\circ}$ and 40 vertical levels. Bottom topography is based on ETOPO2 (Sindhu et al. 2007), the minimum depth of the ocean is set to $15 \mathrm{~m}$ and ocean points shallower than $15 \mathrm{~m}$ are deepened to the minimum depth. Tracer fields are relaxed to climatological values (Chatterjee et al. 2012 ) with a time scale of 30 days in the $3.5^{\circ}$ sponge layer at the eastern and southern open boundaries; no restoration is applied elsewhere. The vertical mixing scheme is KPP of Large et al. (1994) with bulk Richardson number is set to 0.3 . For horizontal mixing, a combination of Laplacian and biharmonic friction with Smagorinsky mixing coefficient of 0.01 (velocity scale $0.04 \mathrm{~m} \mathrm{~s}^{-1}$ ) and 0.1 (velocity scale $0.00 \mathrm{~m} \mathrm{~s}^{-1}$ ), respectively, has been used.

The model is forced by the daily TropFlux wind field for 2000-2014, a period during which moored observations under the RAMA program are available. The forcing fields such as radiative fluxes (long wave and short wave), air temperature and specific humidity are obtained from TropFlux. Precipitation is from the NCEP/NCAR reanalysis (Kalnay et al. 1996) while river inputs are introduced into the top $10 \mathrm{~m}$ as runoffs from Papa et al. (2010) and Vörösmarty et al. (1996). Monthly climatology of the surface Chl from SeaWifs is used to calculate the short-wave penetration into the ocean (see table 1 for more detail of the forcing fields).

\subsection{Numerical experiments}

The model is initialised using climatological temperature and salinity from the north Indian Ocean Atlas (Chatterjee et al. 2012) and spun-up for a 40 years using climatological forcing fields derived based on 2000-2014 interannual forcing. Once the model achieved its quasi-steady state, it is forced with interannual forcing for 2000-2014. This is the most complete solution in the suite and is referred as solution MOMCR. Further, in order to understand the comparative effect of semiannual and intraseasonal winds on the interannual variabilities of the WJs, we carried out the couple of idealised experiments using MOM4p1. In one of such experiment the model is forced by the 120day low-pass filtered zonal and meridional wind stresses and are referred as MOM120lo; therefore, considering the linear nature of the central and eastern EIO (Han et al. 1999, 2001, 2011; Han 2005; Miyama et al. 2006; Nagura and McPhaden 2012), we expect the solution will be dominated by the seasonal/annual variability. In another experiment, in order to account for the intraseasonal variability, model is forced by the 120-day highpass filtered interannual wind stresses and are referred to as MOM120hi. However, for MOM120hi experiment, in order to avoid any drift in the model background state, in the absence of seasonal wind forcing, model is initialised every year using the model state from MOMCR for 1st January of the corresponding year. Additionally, we have averaged over the entire interannual simulation period of MOMCR, MOM120lo, MOM120hi to get the climatological solutions and hereafter referred as CLIM, CLIM120lo and CLIM120hi, respectively. Specific physical processes that are isolated by each of the above solutions are discussed in detail in section 4 and a list of experiments is given in table 2 .

\subsection{Filters and wavelet}

To focus our analysis on intraseasonal-to-seasonal time scales, we have employed a fourth-order low-pass recursive Butterworth filter. The Butterworth filter is preferred as it is maximally flat in the pass-band and provides virtually no 
Table 2. List of experiments.

\begin{tabular}{ll}
\hline $\begin{array}{l}\text { Name of the } \\
\text { experiment }\end{array}$ & \multicolumn{1}{c}{ Forcing characteristics } \\
\hline $\begin{array}{l}\text { MOMCR } \\
\text { MOM120lo }\end{array}$ & $\begin{array}{l}\text { Wind stress from 2000-2015 QSCAT/ASCAT winds } \\
\text { 120-day low-pass filtered wind stress for 2001-2014 } \\
\text { MOM120hi }\end{array}$ \\
$\begin{array}{l}\text { 120-day high-pass filtered wind stress for 2001-2014 and model is } \\
\text { initialised every 1st January using MOMCR }\end{array}$ \\
CLIM & Climatology derived from MOMCR solutions of 2000-2014 \\
CLIM120lo & Climatology derived from MOM120lo solutions of 2000-2014 \\
CLIM120hi & Climatology derived from MOM120hi solutions of 2000-2014 \\
CLIMdiff & Difference of solution CLIM and solution CLIM120lo \\
CLIM120lo & 120-day high-pass filter of solution CLIM120lo \\
\hline
\end{tabular}

distortion of the low-frequency component. For the semiannual/seasonal component of the wind stress, the low-pass Butterworth filter of a cut-off period of 120 days is applied. Furthermore, the intraseasonal signal is computed with the highpass filter with a 120 days cut-off. Note here that Butterworth filter ensures that energy of the spectrum goes to half at the cut-off period and thus, 120-day low-pass filtered signal will have a weaker tail of high-frequency signals below 120day period. Similarly, a 120-day high-pass signal will lose some energy close to the cut-off period. Hence, we opted to employ a broader window than the intraseasonal band.

In order to illustrate the dominant time scales of equatorial zonal currents and zonal wind stress, we have also used a wavelet analysis tool based on Morlet wavelet function (Popiński et al. 2002). Morlet wavelet is especially convenient for analysing signals with a wide range of dominant frequencies which are localised in different time intervals.

\section{Observations and model control run}

Here, we review the observed interannual variability of WJs and validate our model's capability to simulate these equatorial features. Since the observed currents from the RAMA data have a gap of about a year during 2009, thus precludes us from applying the spectral analysis over the entire data record.

The eastward WJs are evident at both the equatorial $\mathrm{ADCP}$ locations $\left(80.5^{\circ} \mathrm{E}\right.$ and $\left.90^{\circ} \mathrm{E}\right)$ in the monsoon transition period i.e., during AprilMay and October-November (figures 1 and S1). The strength of these jets can go up to $1-1.6 \mathrm{~m} \mathrm{~s}^{-1}$ with maximum variability generally confined to the upper $100-120 \mathrm{~m}$ of the water column. Note that the zonal current shows a large spatial and temporal variability. The signal at $80.5^{\circ} \mathrm{E}$ is dominated mainly by the semiannual signal, whereas at $90^{\circ} \mathrm{E}$ the energy in the semiannual band reduces significantly and signals are primarily dominated by the intraseasonal variability (figure 2). Moreover, at both locations, the strength (figures 1 and S1) and the vertical extent (figure not shown) of the jet display large interannual variability. In the eastern EIO $\left(90^{\circ} \mathrm{E}\right)$ spring jet is particularly stronger for the years 2002, 2003, moderate during 2004, 2005 and 2013 and weaker (or absent) during the rest of the years. Whereas during fall WJs are generally weaker at this location. On the other hand, central Indian Ocean $\left(80.5^{\circ} \mathrm{E}\right)$ shows a similar interannual characteristics, but here fall jets are equally strong for almost all the years.

The comparison of the MOMCR simulated zonal current with observations suggests that the model does very well in capturing the observed seasonal/intraseasonal variability along the equator (figures 1 and S1). The correlation between them is 0.91 and 0.82 in the central and eastern EIO, respectively. Perhaps, the lower correlation in the eastern part is owing to the large intraseasonal variability there. Moreover, as observed, MOMCR also suggests a similar spatial/temporal variability along the EIO (figure 2), except the fact that annual signal is much stronger in the model as opposed to observation.

Nevertheless, observation and model simulations do suggest a dominance of the intraseasonal variability along the eastern part of the EIO and thus, indicate the possible influence of intraseasonal forcing on the strength and variability of WJs. 


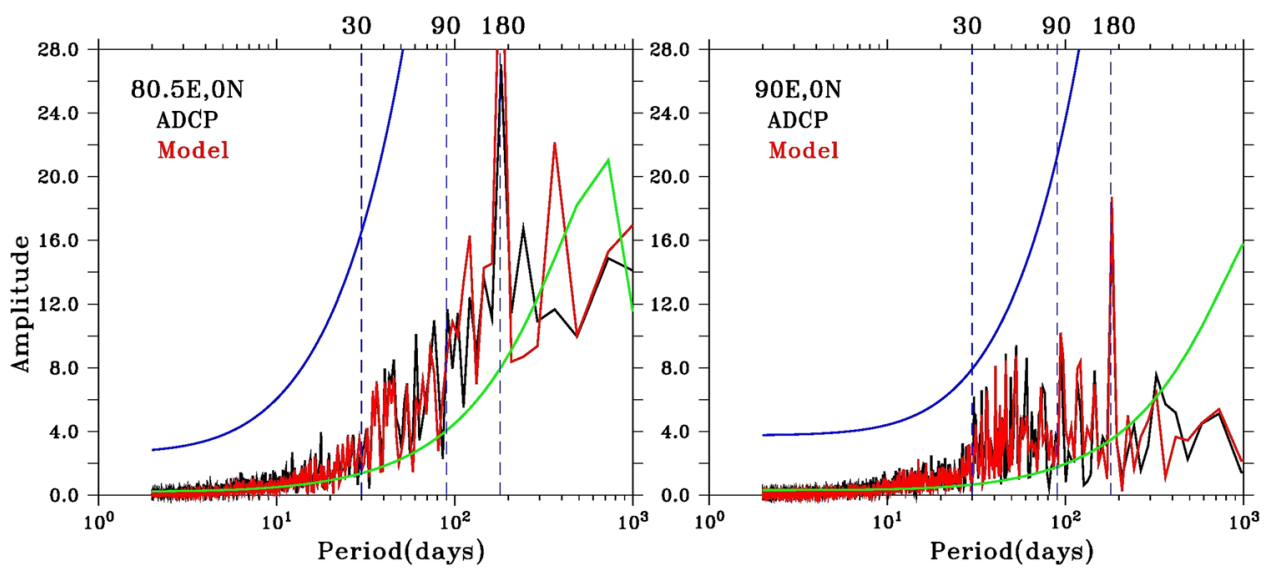

Figure 2. The FFT amplitude spectrum for the observed near surface $(40 \mathrm{~m})$ zonal current at the central $\left(80.5^{\circ} \mathrm{E}\right.$, left panel) and eastern $\left(90^{\circ} \mathrm{E}\right.$, right panel) EIO. The blue curve show the upper and the green curve show the lower limit of 95\% significance level, respectively. Ratio of amplitudes in the intraseasonal band (30-90 day) to semiannual band (160-200 day) at $80.5^{\circ} \mathrm{E}$ and $90^{\circ} \mathrm{E}$ are 0.26 and 0.51 , respectively. Note here that in order to calculate spectra, data record of length 2005-2008 (2001-2008) is considered for the central (eastern) EIO.

\section{Results}

In this section, we describe the variabilities of the observed currents in central and eastern EIO with more focused discussion on WJ dynamics, we use both observational data sets and a suite of model simulations (described in section 2.3).

\subsection{Observations}

In order to understand the interannual variability of the spring and fall jets we have analysed the wavelet spectrum of zonal winds, zonal currents and wavelet coherence analysis (WCA) between them at the central and eastern EIO (figures 3 and 4). The WCA not only determines the correlation between two signals but also provides the phase relationship between them.

In the central EIO, zonal winds are dominated by the semiannual band of the spectrum with the strongest energy peak seen during 2005 followed by the weakest peak in the summer of 2006 (figure 3). Moreover, the significant intraseasonal variability is evident in almost all the years studied here. The variability shows a seasonal pattern with maxima occurring mostly during spring and fall. Zonal currents also exhibit similar collocated spectral peaks for the semiannual and intraseasonal bands during 2005; but the energy weakens/disappears from fall 2006, particularly for the semiannual band due to anomalous easterlies driven by IOD events. Consequently, during 2005, the WCA shows a strong in-phase coherence between the winds and the currents for the semiannual band. Moreover, the strong coherence is observed for the intraseasonal band in all years except during fall 2006 . Surprisingly, even though the spectral power of the semiannual period for both the fields is much stronger compared to the intraseasonal period, the WCA suggests equivalent amplitude for both the bands indicating the fact that the weaker intraseasonal winds strongly couple with the intraseasonal currents in the EIO. Perhaps, due to the fact that smaller fetch of the intraseasonal winds fit well with the length scale of the intraseasonal Kelvin waves and thus efficiently excite them (Chatterjee et al. 2013).

In the eastern EIO, in addition to the semiannual and intraseasonal bands, zonal winds also show strong annual period across the years (figure 4). Annual peak is, in fact, stronger than the semiannual peak in the wind spectrum. However, the near-surface zonal current shows the strongest peak for the semiannual band. Han et al. (1999) attributed this stronger semiannual response to the prevailing zonal structure of the semiannual winds, geographic resonance and mixed layer shear flow of the EIO. Moreover, note that the intraseasonal band of both the fields, winds and currents, shows a stronger amplitude at $90^{\circ} \mathrm{E}$ compared to that at $80.5^{\circ} \mathrm{E}$ for most of the years. Unlike central EIO, in the eastern EIO, the WCA suggests no coherent relationship between the equatorial winds and currents in the annual/semiannual band, indicating that the overlying semiannual winds are not the primary cause of the semiannual currents in the eastern EIO and, in fact, are remotely forced west of the $90^{\circ} \mathrm{E}$. Furthermore, they are highly 


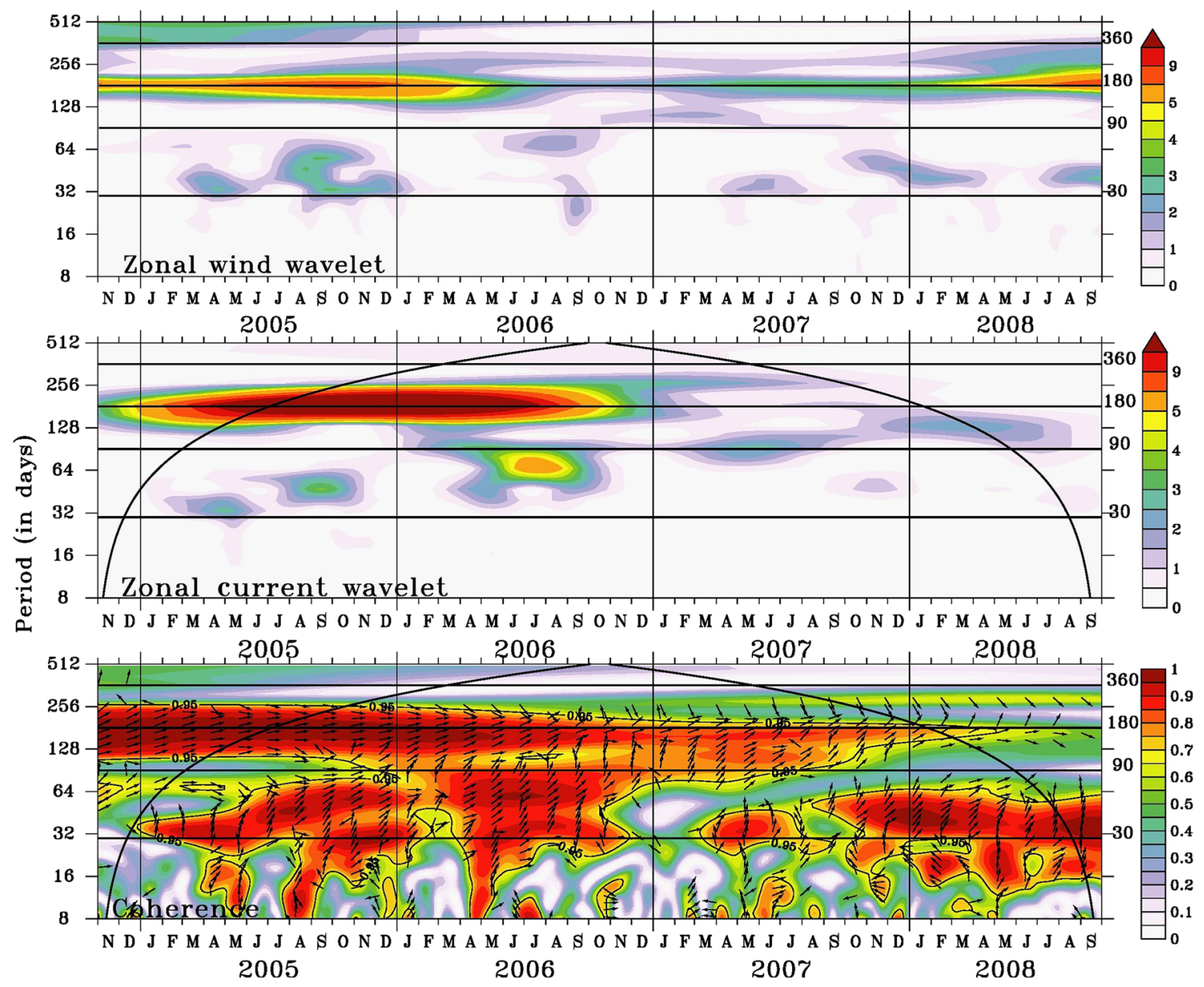

Figure 3. Morlet wavelet power spectra of the equatorial surface zonal wind $\left(10^{-4} \mathrm{~m}^{2} \mathrm{~s}^{-2}\right.$, top panel) and near surface (40 m depth) zonal current $\left(10^{-8} \mathrm{~m}^{2} \mathrm{~s}^{-2}\right.$, middle panel) observed at $80.5^{\circ} \mathrm{E}$. The bottom panel represents the wavelet coherence between them. The arrow shows relative phase relationship with in-phase (anti-phase) pointing towards right (left). Wind leads (lags) the current in anticlockwise (clockwise) direction. The black curve marks the cone of influence for the wavelet spectra. The horizontal black lines mark the 30-, 90-, 180- and 360-day period.

coherent with each other in the intraseasonal band, primarily during spring of 2001-2005 when the stronger WJs are observed in the ADCP records (figure 1). This substantial coherence between the zonal current and the zonal wind variability for the 30-90-day period band indicates the considerable contribution of intraseasonal winds in driving the zonal current in the eastern EIO.

\subsection{Model solutions}

\subsubsection{Climatological solutions}

For understanding the annual cycle of the WJs and its relation to the direct wind forcing, here we have analysed various climatological solutions. Figure 5 shows that the 120-day low-pass filtered (seasonal/semiannual) climatological zonal wind stress field exhibits two strong westerly peaks during April-May and November-December along the entire stretch of the EIO. During April-May, the seasonal/semiannual winds are particularly stronger within $65-90^{\circ} \mathrm{E}$, but weaken significantly close to the eastern boundary. However, during November-December, westerly winds are stronger in the eastern part of the basin, with enhanced westerly winds observed along the entire EIO except close to the western boundary. In contrast, the 120-day high-pass filtered (intraseasonal) wind stress shows a sprinkle of strong westerlies throughout the year, but the strength is notably much higher during the later part of April to early part of May and stretches across almost the entire EIO. This intraseasonal band also shows stronger westerlies during November, but the strength is much weaker compared to spring.

As a response to the wind in early May, the jet in the solution CLIM is confined to the east 


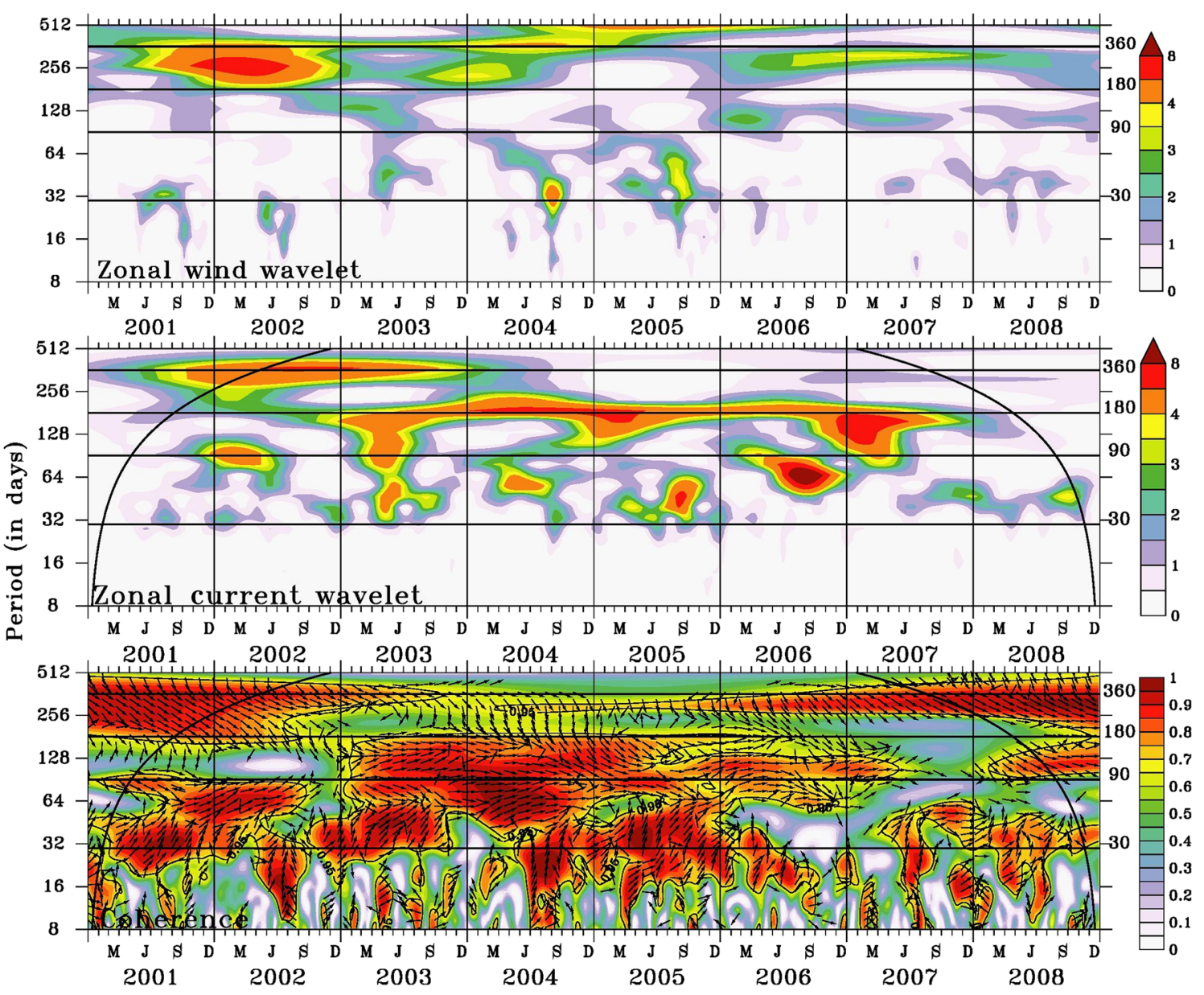

Figure 4. Same as figure 3 , but for $90^{\circ} \mathrm{E}$.

of $55^{\circ} \mathrm{E}$ of the EIO with maximum strength of about $1.7 \mathrm{~m} \mathrm{~s}^{-1}$ at around $80^{\circ} \mathrm{E}$ (figure 6). The solution CLIM120lo exhibits a similar response, except the fact that jet disappears east of $85^{\circ} \mathrm{E}$ and also the maximum amplitude of the jet is weaker (i.e., around $1.2 \mathrm{~m} \mathrm{~s}^{-1}$ ) than the CLIM solution. Notably, the stronger semiannual response is collocated with the stronger semiannual westerlies. The disappearance of the signal in the eastern part of the basin is likely due to the Rossby wave reflection off Sumatra coast (McCreary et al. 1993) and downward propagation of energy (McCreary $\mathrm{Jr}$ 1984) of the free Kelvin wave generated outside the forcing region. On the other hand, the solution CLIM120hi shows a significant amplitude $\left(0.4-0.7 \mathrm{~m} \mathrm{~s}^{-1}\right)$ east of $70^{\circ} \mathrm{E}$. However, owing to the presence of intraseasonal westerlies, the jet is extended further east to $95^{\circ} \mathrm{E}$ into the EIO. In contrast, during fall, the jet in the solution CLIM is spread over a much larger region starting from the western boundary of the equatorial basin. Moreover, the width of the jet is also much narrower compared to spring, particularly in the eastern
EIO. The solution CLIM120lo is almost a close replica of the solution CLIM and the amplitude of the jet is much stronger compared to spring. Also, unlike spring, fall jet extends up to the eastern boundary of the basin, a forced response of the semiannual zonal wind stress along the EIO. Further, the positive zonal current in the solution CLIM120hi becomes either very weak or absent.

Moreover, note that the sum of the solutions CLIM120lo and CLIM120hi is nearly equal to solution CLIM. Figure 6 shows the difference of CLIM and CLIM120lo (hereafter referred as CLIMdiff). For a completely linear system, one would expect the filtered response (CLIMdiff) to be identical to the solution forced by the filtered winds (CLIM120hi). We find that CLIMdiff is slightly weaker than the CLIM120hi, particularly in the eastern EIO. One possible reason for these discrepancies between CLIMdiff and CLIM120hi is the anomalous shoaling of the mixed layer close to the eastern boundary of the basin in the CLIM120hi experiment. As a result, the forced response of the intraseasonal winds is stronger in the CLIM120hi 

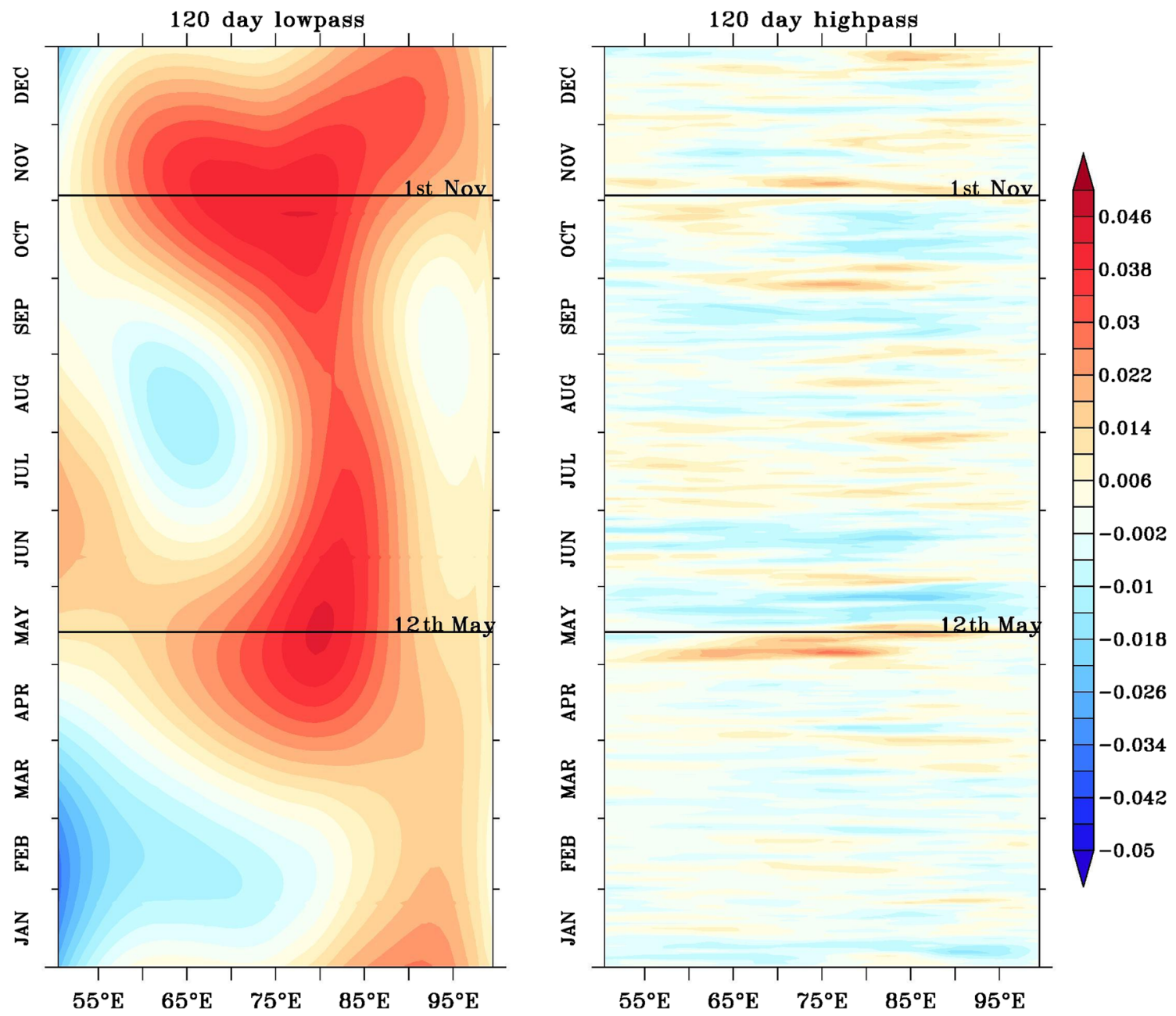

Figure 5. Climatological wind stress with period above 120 days (left panel) and period below 120 days (right panel). Horizontal lines represent 12th May and 1st November, the peak of the spring and the fall WJ, respectively.

experiment than the control run, particularly close to the eastern boundary of the basin. Another reason for these differences may be attributed to internal variabilities of the system as earlier noted by Han (2005) and Nagura and McPhaden (2014). In order to understand the influence of instability in the weaker response of the CLIMdiff in the eastern EIO, 120-day high-pass field of the CLIM120lo (hereafter referred as CLIM1201o ${ }^{\text {hi }}$ ) for spring and fall period is shown in figure 6 (bottom panels). Since the wind forcing for the CLIM120lo experiment has no energy below 120-day period, any high-frequency response below 120-day period should be due to the internal variability of the system. However, CLIM120lo ${ }^{\text {hi }}$ exhibits an order of magnitude weaker response compared to the direct wind forced response CLIM120hi, suggesting that instability might be important to amplify the signal in the eastern EIO, but direct wind forcing is still the dominant forcing along the central and eastern
EIO. Thus, even though nonlinear term exists in the OGCM, it does not include the nonlinear interactions between 'intraseasonal wind forcing' and 'seasonal surface currents and equatorial undercurrents', which are shown to be important in producing the rectified effects on the WJs surface strength and transport (Han et al. 2004).

Hence, in spite of weaker semiannual signal during spring compared to fall, large intraseasonal signal amplifies the WJ during spring; therefore, allows both WJs (spring and fall) to be of comparable magnitude along the EIO, particularly in the eastern EIO.

\subsubsection{Interannual solutions}

To better understand the relative role of the intraseasonal and semiannual winds on the dynamics of the WJs, we rely on the results from the MOM120lo and MOM120hi experiments. Figures 


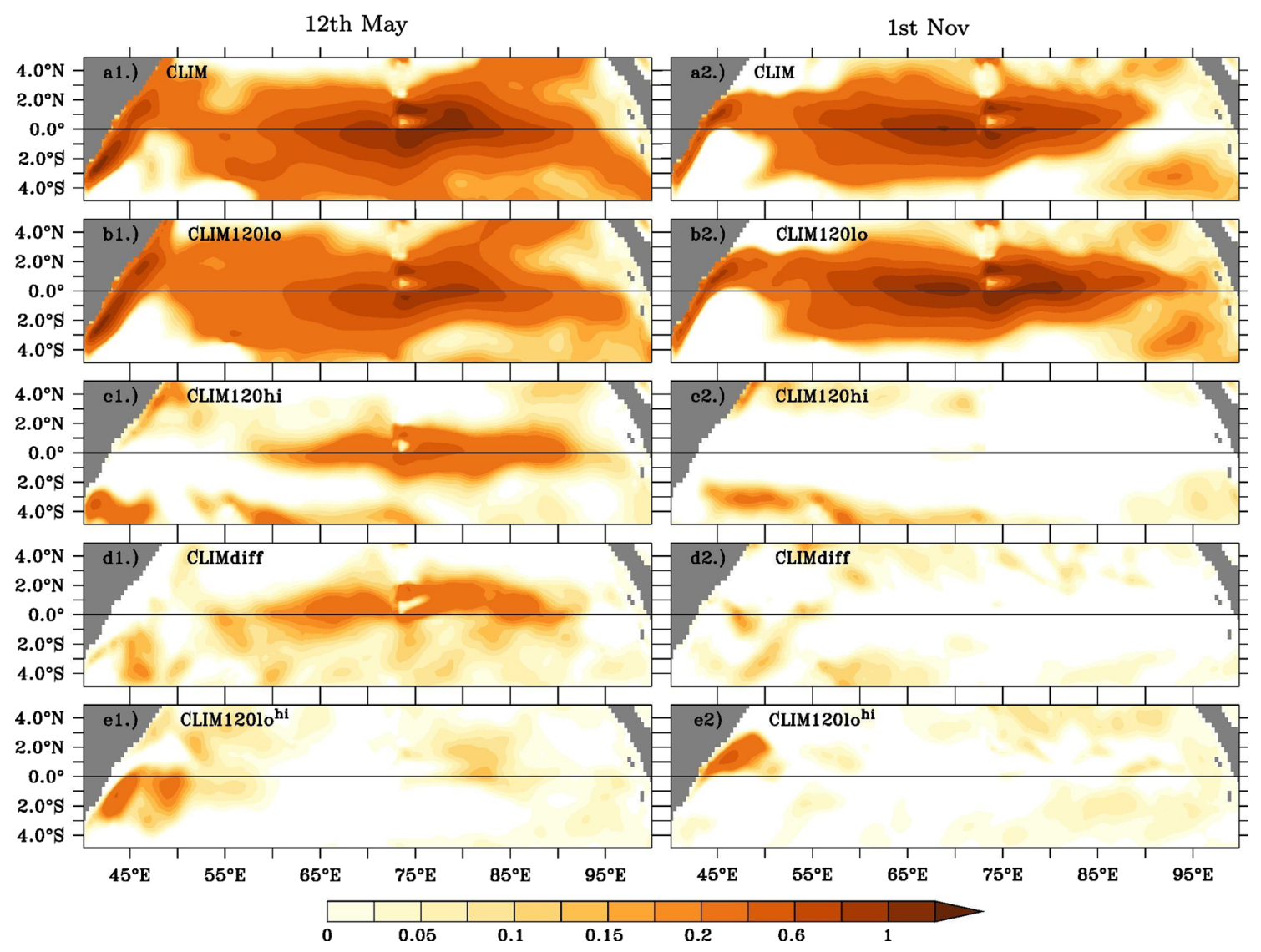

Figure 6. Comparison of the snapshots of zonal current $\left(\mathrm{m} \mathrm{s}^{-1}\right)$ from solution CLIM (a), CLIM120lo (b), CLIM120hi (c), CLIMdiff (d) and CLIM120lo ${ }^{\text {hi }}(\mathbf{e})$ for the spring and fall.

7 and 8 (also figures $\mathrm{S} 2$ and $\mathrm{S} 3$ ) show the zonal currents from the solution MOMCR, MOM120lo and MOM120hi. Note that the addition of MOM1 20lo and MOM120hi solutions does not compare to the MOMCR solution perfectly, a detailed discussion on the possible cause of these discrepancies is given in section 4.2.1. Nevertheless, strong overlapping between the MOMCR solution and the addition of MOM120hi and MOM120lo supports the quasi-linearity of the system as earlier noted by many (Han et al. 1999; Miyama et al. 2006; Nagura and McPhaden 2012) and therefore, this technique can give the essence of each of the periodic band's contribution towards the total variability along the EIO.

At $80.5^{\circ} \mathrm{E}$, the solution MOM120lo follows the solution MOMCR more closely compared to the solution MOM120hi. The overall correlation between MOMCR and MOM120lo is 0.83, which is much higher than the correlation between MOMCR and MOM120hi (0.55). This indicates that the zonal currents are predominantly driven by the local seasonal/semiannual winds in the central EIO which is in agreement with observations. In contrast, at $90^{\circ} \mathrm{E}$, the solution MOM120lo is much weaker and the solution MOM120hi determines most of the variability seen in the MOMCR. As expected, the correlation between MOMCR and MOM120lo is reduced to 0.6, whereas it increases considerably to 0.68 between the MOMCR and MOM120hi here. Moreover, note that irrespective of the location, both the frequency bands i.e., semiannual and intraseasonal are always in phase and thus interfere constructively to achieve the observed peak in the strength of the WJs. For example, during spring 2003, when the strength of the jet is strongest of the decade, the solution MOM120hi determines the steepness of the jet, but the solution MOM120lo contributes constructively as a background current (figure 8).

In addition, the wavelet spectra of the equatorial zonal current (figures 9 and 10) indicate a dominant semiannual variability during spring and fall of 2002-2004 and 2011-2013 with the maximum amplitude restricted to $55-80^{\circ} \mathrm{E}$; further east, spectral energy decreases rapidly. In contrast, intraseasonal period shows the strongest spectral peak in the eastern EIO and energy decreases westward. In 


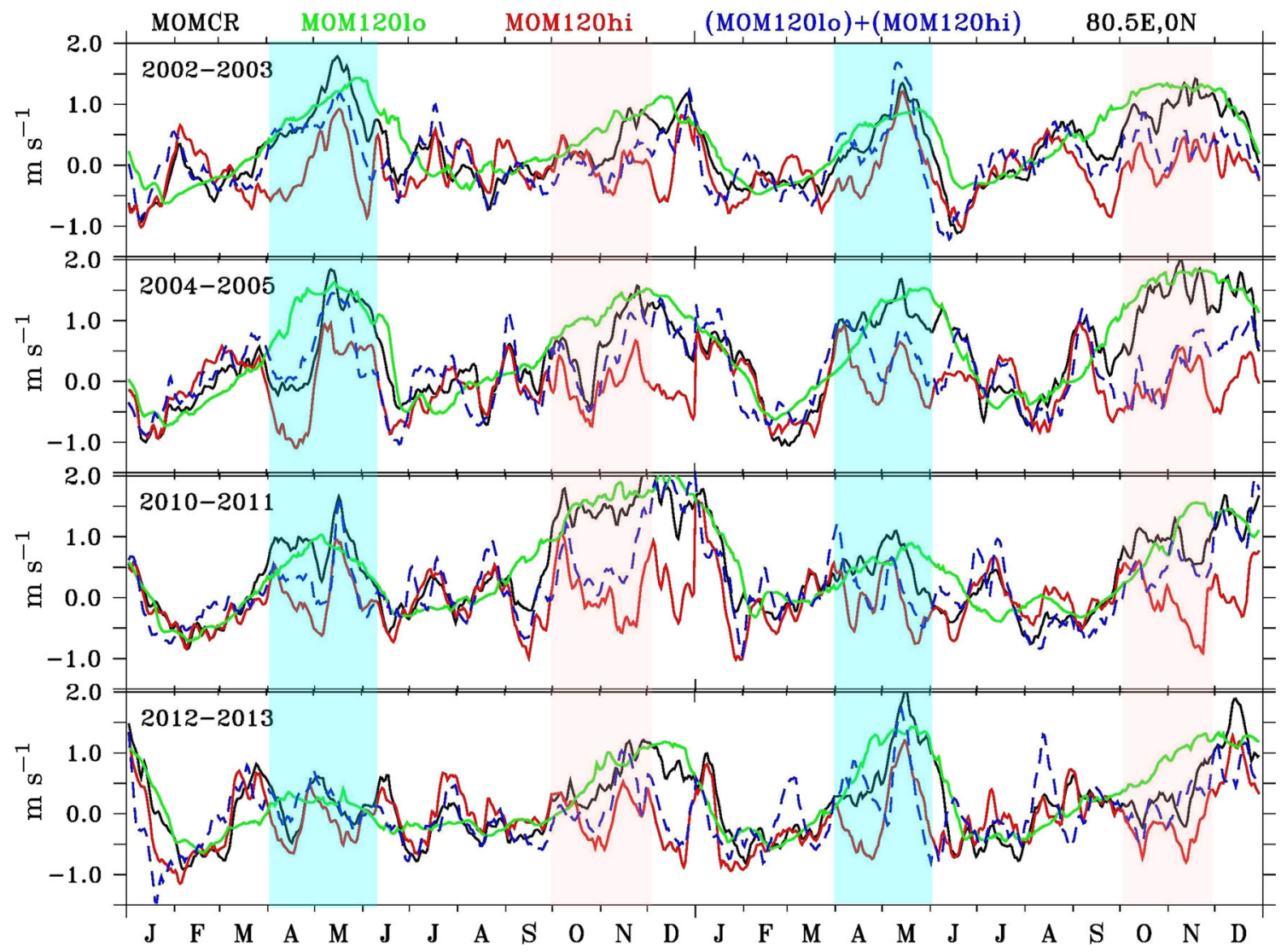

Figure 7. Comparison of surface zonal current from MOMCR, MOM120lo and MOM120hi at 80.5 E. Colour shading mark the spring and fall periods. Note: IOD years are shown in the supplementary figure S2.

general, the intraseasonal energy is stronger during spring compared to fall for all the years. Also, the spectral energy for both semiannual and intraseasonal period bands is weakest during 2006-2008 owing to the positive IODZM. One of the striking feature to note here is the intraseasonal variability in the eastern EIO that is maximum during 2003 and 2013 of all the other years and consequently we also observe the strongest spring jets of the decade in these 2 years.

\section{MJO factor}

In the previous sections, we have shown that there exist significant intraseasonal currents, driven by intraseasonal winds, which influence the strength and variability of WJs. MJOs account for most of the observed intraseasonal variability in the tropical Indian Ocean, particularly during NovemberMay, which is the active phase of MJO (Lau and Waliser 2011). In this section, we have elaborated the influence of MJOs on the strength of equatorial zonal currents, particularly for WJs.
MJOs are 30-90-day eastward propagating convection and associated winds from the western Indian Ocean across the maritime continent into the equatorial Pacific (Madden and Julian 1972). MJO phases can be defined in terms of the timing and locations of its centre of convection (maximum rainfall anomalies) and the associated wind fields. Most commonly used MJO phases are based on the RMM index of Wheeler and Hendon (2004). To clearly observe the MJO association with zonal currents, the RMM phases of MJO are analysed here in context of WJs. Figure 11 shows the strength and location of the MJO during 2000-2014. Note here that MJO phases 2-4 are important in this context as they correspond to the convection in the eastern EIO and over the maritime continent and therefore, lead to intraseasonal westerly wind bursts along the EIO. The year-wise analysis of the MJO index shows significant MJO activity during the spring of 2002-2005, 2010-2011 and 2013-2014 (figure 11). This is the time when most of the relatively stronger spring WJs are observed (figures 1 and S1) in the last two decades. Moreover, note that during fall the strength of the MJO is either 


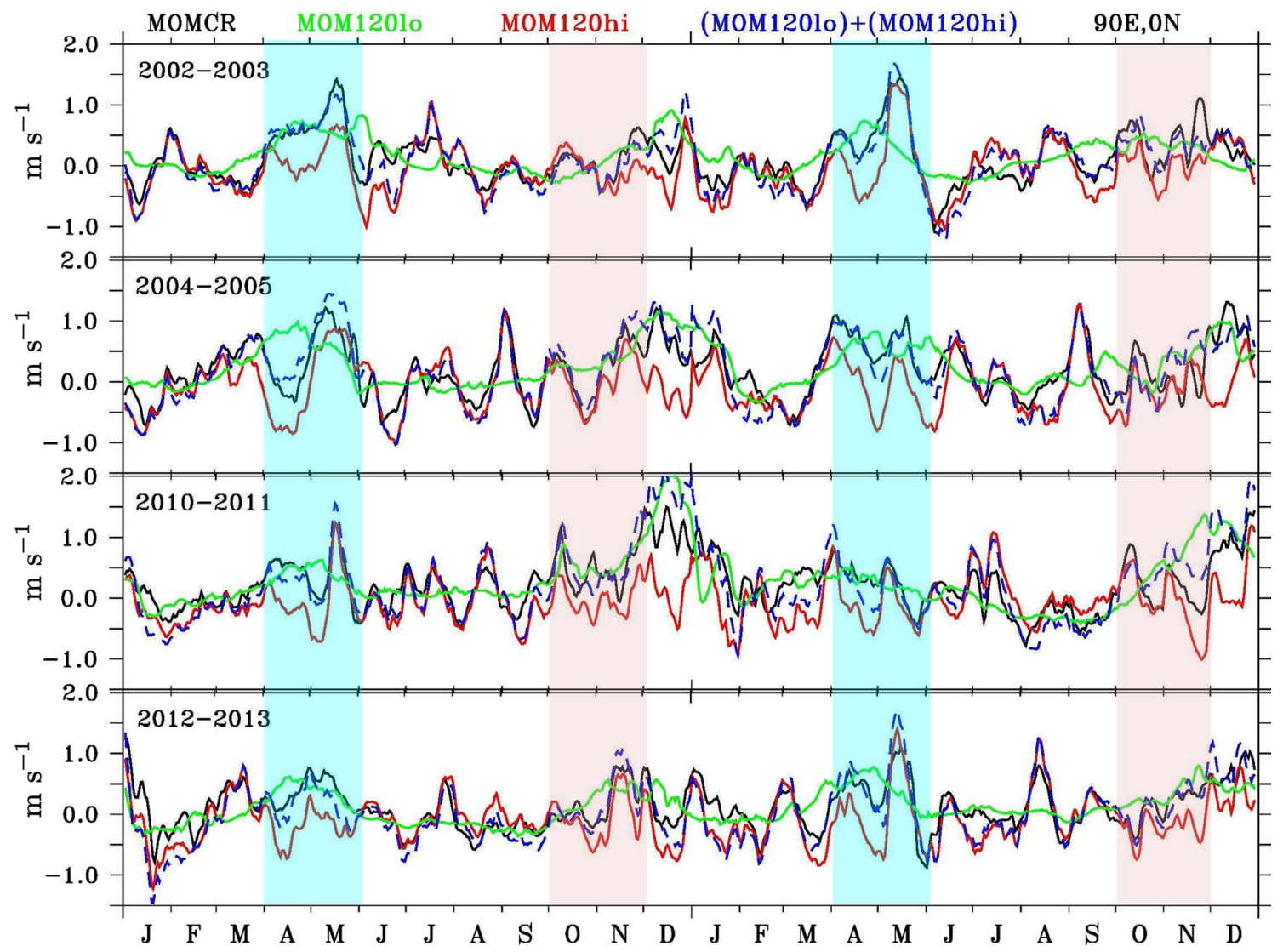

Figure 8. Same as figure 7 , but for $90^{\circ} \mathrm{E}$.

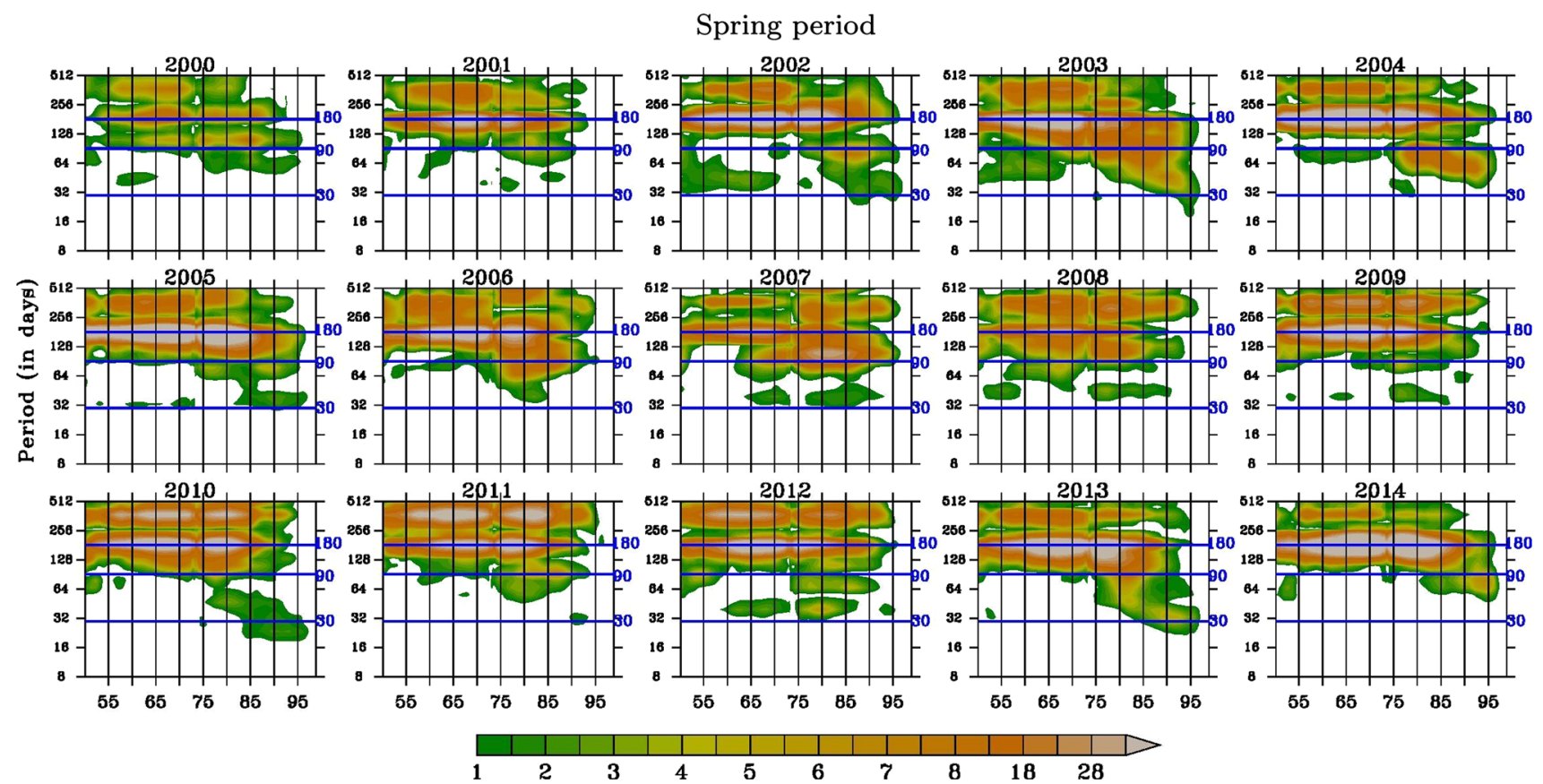

Figure 9. Wavelet spectra $\left(10^{-4} \mathrm{~m}^{2} \mathrm{~s}^{-2}\right)$ of the zonal current from MOMCR along the equator averaged over spring WJ period (1 May-30 May) and over $1.5^{\circ} \mathrm{S}-1.5^{\circ} \mathrm{S}$ longitude band. The horizontal lines represent the 30-, 90- and 180-day period. The dominant frequency is semiannual band across the entire EIO. In addition, significant intraseasonal variability is also noticed confined in the central and eastern EIO. 


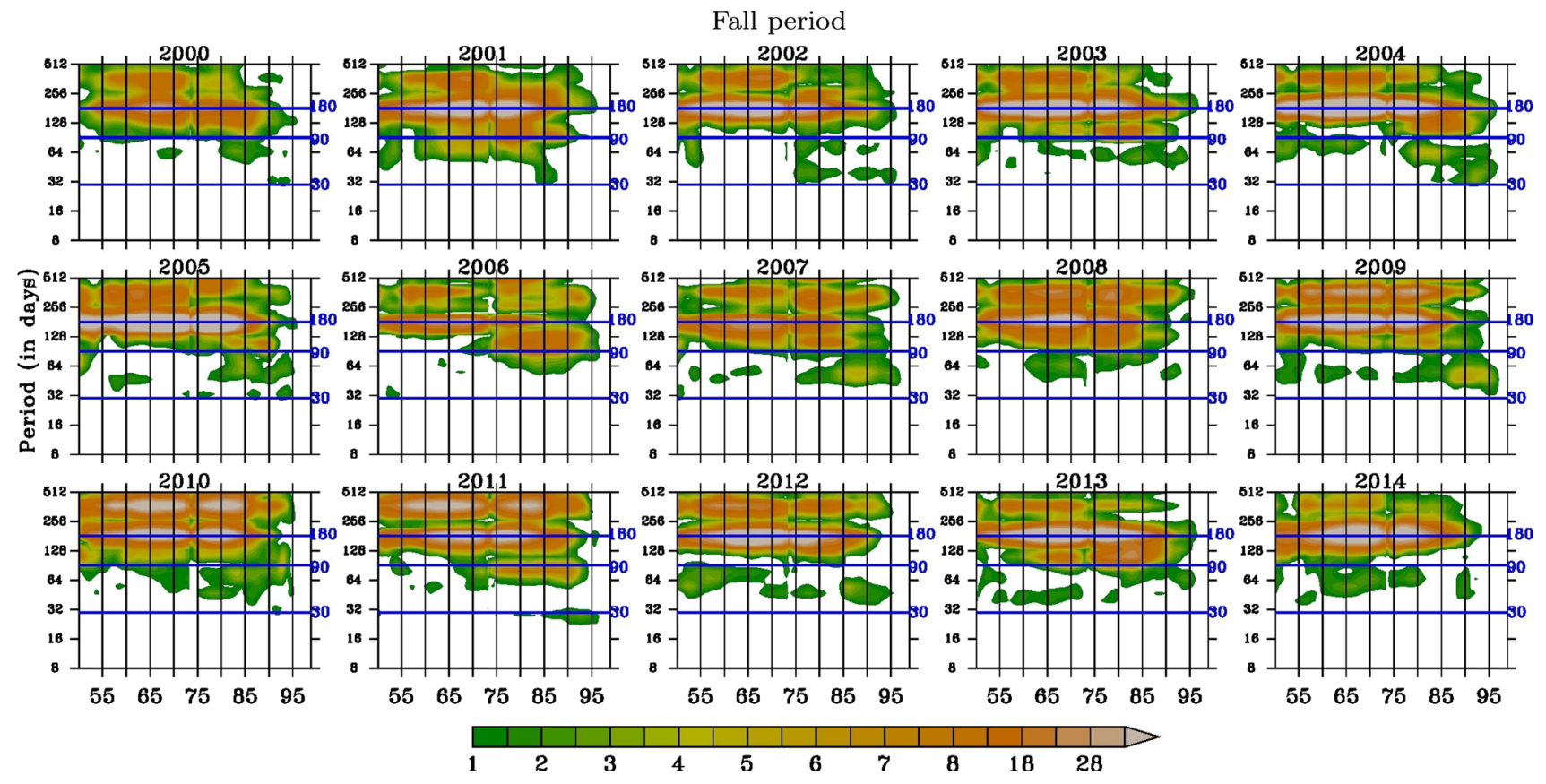

Figure 10. Same as figure 9, but for the fall WJ period (1-30 November).

very weak or active in the western Pacific region across all the years (figure S4). This indicates that during spring the intraseasonal westerlies associated with the MJO influence the strength of the WJs; whereas, during fall, lack of MJO activity in the EIO weakens the presence of intraseasonal forcing there. Further, weakening of MJO strength during 2006-2008 also coincides with the weaker WJs in the central and eastern EIO.

A close look at the MJO index (figure 11) also suggests that the strength of the spring time MJO activities over the phases 2-4 are comparable for all years for 2002-2005, 2010-2011 and 2013-2014 with slightly stronger magnitudes during spring of 2004 and 2005. However, observations and model simulations indicate stronger WJs during spring of 2002, 2003 and 2013; moderate during 2004-2005, 2010, 2014; and absent during 2011. One possible reason for this discrepancy in oceanic response to MJO winds is that during spring of 2002-2003 eastward propagation speed of MJO-induced convection is relatively slow and therefore, associated westerly wind field over the eastern Indian Ocean persist for a longer time driving very strong equatorial jet there (figure 11). On the other hand, in the subsequent years, even though convection is stronger, the MJO propagation speed is much faster. Therefore, wind field is imposed on the ocean surface for much shorter time leading to inefficient and weaker excitation of equatorial jets. Further, the analysis of the 30-90-day filtered OLR and the associated surface zonal wind vectors, which are good proxies for MJO-related convection (figure 12), suggests that during 2002, 2003 and 2013 MJO convection is situated over the equator and therefore, wind field is symmetric about the equator, whereas during 2004 and 2005 convection is stronger, but it is off the equator. Moreover, during 2011 MJO convection appears in the bay, completely away from the equator. Since it is known that symmetric zonal wind field is necessary in order to efficiently excite WJ along the equator (Yoshida 1960), strongest WJs are observed during 2002-2003 and 2013. Whereas during 2004 and 2005 convection is stronger, but it is slightly off the equator, resulting in a weaker symmetrical component of the zonal wind field about the equator and drives a moderate WJ in the EIO. Similarly, in the absence of no symmetrical wind component no spring jet is observed during 2011. Note here that during rest of the years the MJOs are either absent or in an unfavourable phase along the EIO leading to an absence or weaker WJs there.

\section{Summary and conclusion}

In this study, we examine the direct wind forced dynamics of the equatorial zonal currents in the Indian Ocean using observations and model simulations. In particular, we explore the distinct contributions of semiannual and intraseasonal wind 


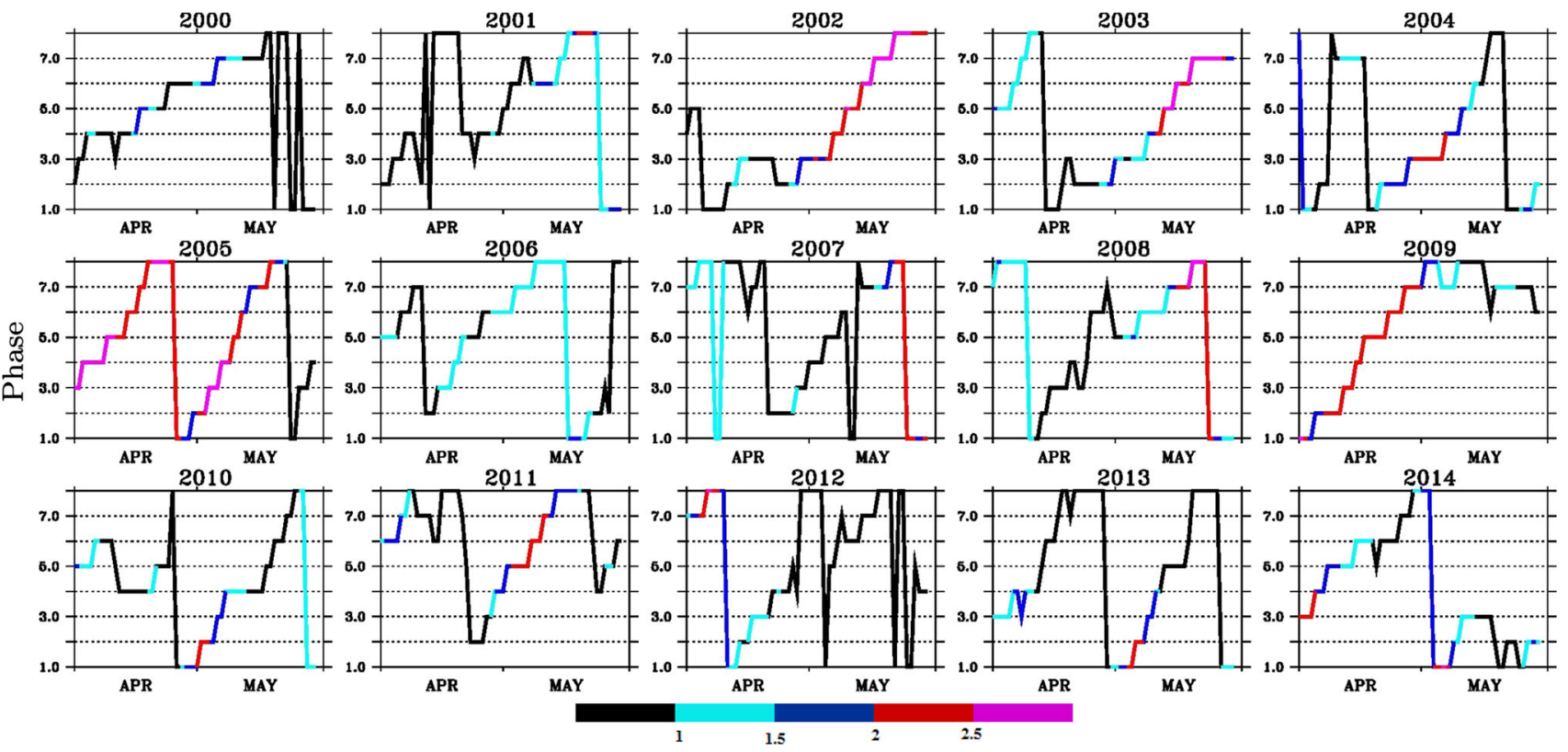

Figure 11. RMM index for the year 2000-2014 during spring period of WJs (April-May). The Y-axis represents phase of the MJO event with phases $2-4$ is over the eastern Indian Ocean and Indonesian continents. Colour represents the strength of the MJO activity and slope of the lines represent the propagation speed of an MJO event across the phases.
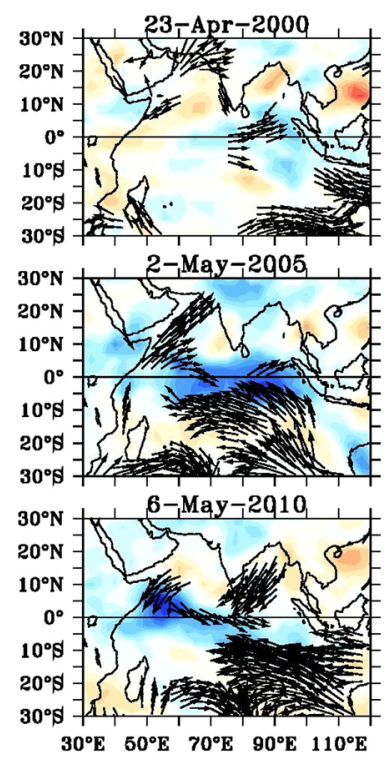
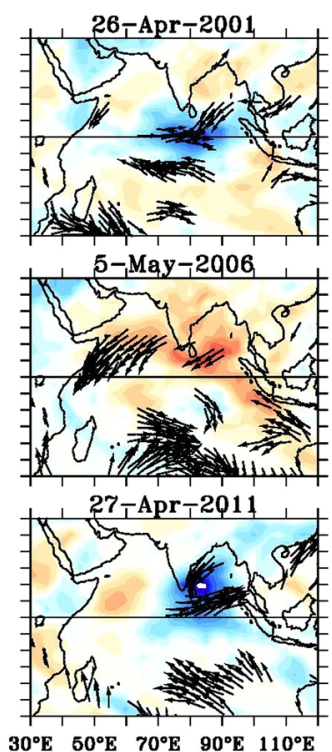

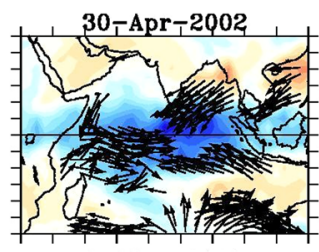

2-May-2907
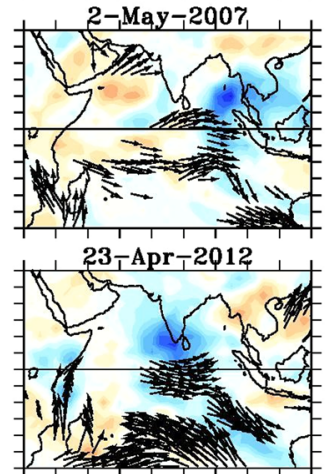
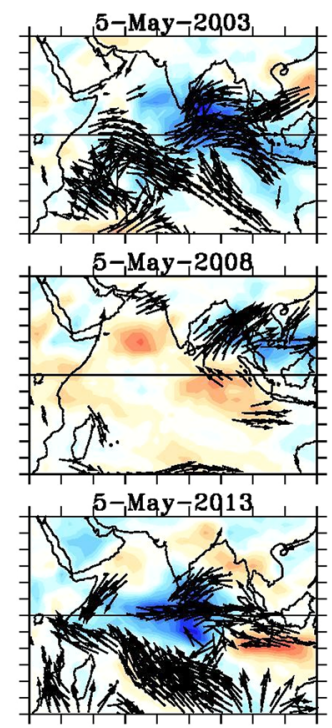
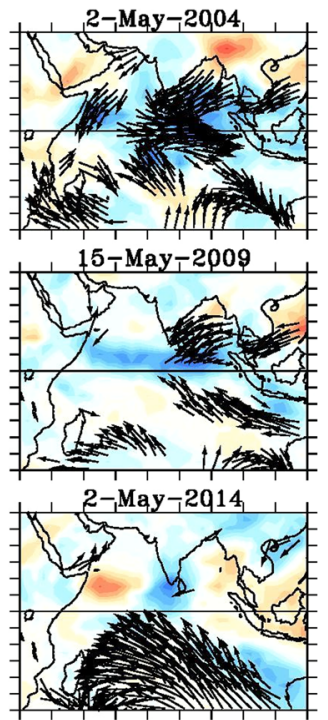

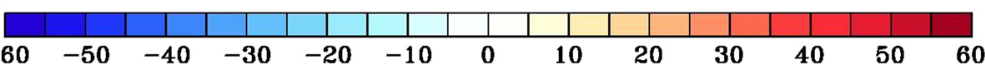

Figure 12. Snapshots of the 30-90-day filtered OLR (shaded, W/ $\mathrm{m}^{2}$ ) and wind stress with magnitude more than 0.02 dyn $\mathrm{cm}^{-2}$ (vector; every 4th vector is plotted) for the day when the strength of the convection and associated wind field is maximum and strong WJs are seen along the EIO.

forcing in the variability of WJs based on observations and model solutions. The model captures the observed interannual variability of the WJs reasonably well (figures 1 and S1) except the fact that model simulated magnitude of the fall jets has a small positive bias, particularly in the eastern EIO. This bias is mainly due to the model's diffused thermocline in the eastern EIO. This is a very well-known problem with model simulations and common to all the state-of-the-art models. A similar problem with the model in the eastern EIO is also noted by Shinoda et al. (2016). These smaller discrepancies between the model and the observations are more related to model deficiencies 


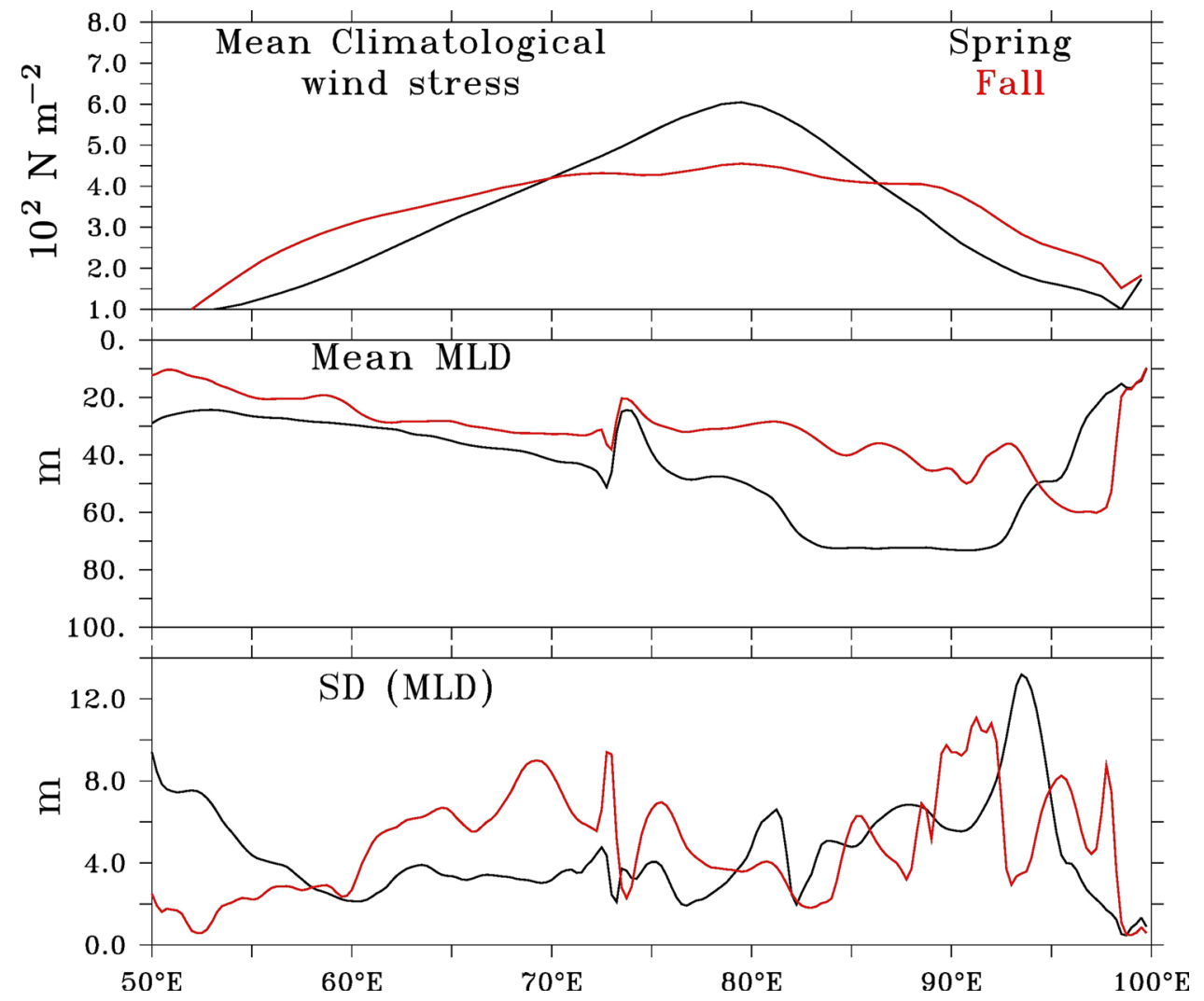

Figure 13. Comparison of climatological mean zonal wind stress (upper panel), mean MLD (middle panel) and standard deviation of MLD (lower panel) along the EIO for the spring (1 May-30 May) and fall (1-30 November).

and also most likely linked to the available forcing as well.

WCA between the observed winds and currents at the equatorial RAMA locations indicates that semiannual currents at the central EIO are strongly coupled with the overlying winds, but, at the eastern part, it is primarily driven by the signals forced in central and western EIO. However, for the intraseasonal band, strong coherency is observed between winds and currents for both the RAMA locations during prevailing spring WJs. This indicates that the significant part of the forcing for the WJs in the EIO is from the intraseasonal frequency band which results in intraseasonal jets during the peak period of the WJs.

The dynamics of the WJs are further examined by various ideal model experiments. We concluded that both semiannual and intraseasonal frequencies determine the variability of the zonal current in the EIO (figures 9 and 10). The semiannual current is the dominating signal throughout the equator with maximum amplitude in the central EIO, but owing to the reflection of equatorial Rossby waves exhibits much weaker energy close to eastern boundary (McCreary et al. 1993).
Whereas, for the intraseasonal signal, the strongest amplitude is located off the eastern boundary of the basin, but amplitude decreases rapidly westward west of $75^{\circ}$ E. Further, the climatological solutions show that the spring jets comprise of significant intraseasonal jets in the central and eastern EIO forced by intraseasonal winds. However, for the fall jet, contribution of intraseasonal forcing is much weaker.

Considering the striking and new result that the intraseasonal component of the $\mathrm{WJ}$ is much stronger in spring, it is natural to focus on the forcing mechanism, i.e., the winds. As shown in figure 13, the westerlies in May are stronger, especially in the western-central EIO and the variance is much higher in the intraseasonal band in May (figure 4). Thus, the direct forcing itself is much stronger at intraseasonal time scales in spring. Not surprisingly, this leads to a deeper MLD in the eastern EIO in spring. Noting the weaker westerlies in the eastern EIO in spring, the deeper MLDs are clearly due to the remote forcing by the downwelling Kelvin waves and the associated deepening of the thermocline and the weakening of the stratification (see, e.g., Shinoda and Hendon 
1998; Waliser et al. 2003). This thermal inertia in May may be of consequence to the lower frequency variability especially considering that the IODZM tends to be in its onset phase during spring and the role of WJ is invoked in earlier studies (Vinayachandran et al. 1999; Annamalai et al. 2003; Han et al. 2006; McPhaden et al. 2015; Wang et al. 2016). The role of the spring WJ and its lowfrequency variability (Joseph et al. 2012) in the IODZM, monsoon variability and ENSO-monsoon interactions need to be understood given the role of intraseasonal wind variability in the spring WJ itself (Wu and Kirtman 2004; Annamalai et al. 2005; Krishnan et al. 2011).

We also find that the interannual variability of spring jets is attributed to intraseasonal variability of the jets. It is noticed that just the presence of active MJOs does not assure a stronger WJ. But the position of MJO associated convection and its phase speed play a very critical role in determining the strength of the spring jets (figures 11 and 12). For example, we observed one of the strongest spring WJs in the last decade for years 2002-2003 and 2013 though there is strong spring time activity seen in the Indian Ocean during many other years like 2004-2005, 2010-2011 and 2014. Notably, during the post-2006 era, the intraseasonal variability is found to be much weaker for most of the years. As a result, in response to weaker MJO activities, the magnitude of the spring jet remains weaker compared to the fall jets, particularly at central EIO (figure S2). This weaker magnitude of the spring jets compared to the fall jets during this period was reported earlier by McPhaden et al. (2015).

In conclusion, we have analysed the detailed wind forced dynamics of WJs in the central and eastern EIO, where the strength of the jet reaches its maximum. We show that although semiannual are the predominant forcing of the WJs, a significant intraseasonal energy is evident during the spring in the central and the eastern EIO. The intraseasonal currents induced by the MJO can superimpose constructively with semiannual currents during the peak time of the spring to obtain the observed strength of the spring jets. Also, the variation in the strength of the intraseasonal spring jets reflects into the interannual variability of the spring WJs. Although, there is considerable interannual variability in the strength and timing of the WJs, the processes identified in this study are active every year.

\section{Acknowledgements}

All the MOM4p1 simulations were carried out on the INCOIS-HPC and on Aditya at IITM, Pune. Ferret is extensively used for analysis and graphics. The MJO index is downloaded from Australian Government Bureau of Meteorology (http://www.bom.gov.au/climate/mjo). Thanks to NOAA/CDC for the OLR data sets and NOAA/ PMEL for the equatorial RAMA ADCP (http:// www.pmel.noaa.gov/tao/data_deliv/deliv-nojava-r ama.html) data sets. This is INCOIS contribution no. 321 .

\section{References}

Alexander M A, Bladé I, Newman M, Lanzante J R, Lau N-C and Scott J D 2002 The atmospheric bridge: The influence of ENSO teleconnections on air-sea interaction over the global oceans; J. Climate 15(16) 2205-2231.

Annamalai H, Murtugudde R, Potemra J, Xie S-P, Liu P and Wang B 2003 Coupled dynamics over the Indian Ocean: Spring initiation of the zonal mode; Deep Sea Res. II, Top Stud. Oceanogr. 50(12) 2305-2330.

Annamalai H, Xie S, McCreary J and Murtugudde R 2005 Impact of Indian Ocean sea surface temperature on developing El Niño; J. Climate 18(2) 302-319.

Chatterjee A et al. 2012 A new atlas of temperature and salinity for the north Indian Ocean; J. Earth Syst. Sci. 121(3) 559-593.

Chatterjee A, Shankar D, McCreary J and Vinayachandran P 2013 Yanai waves in the western equatorial Indian Ocean; J. Geophys. Res. - Oceans 118(3) 1556-1570.

Chatterjee A, Shankar D, McCreary J, Vinayachandran P and Mukherjee A 2017 Dynamics of Andaman sea circulation and its role in connecting the equatorial Indian ocean to the Bay of Bengal; J. Geophys. Res. - Oceans 122 3200-3218.

David D T, Kumar S P, Byju P, Sarma M, Suryanarayana A and Murty V 2011 Observational evidence of lowerfrequency Yanai waves in the central equatorial Indian Ocean; J. Geophys. Res. - Oceans 116(C6) 1-17.

Deshpande A, Gnanaseelan C, Chowdary J and Rahul S 2017 Interannual spring wyrtki jet variability and its regional impacts; Dyn. Atmos. Oceans 78 26-37.

Gnanaseelan C, Deshpande A and McPhaden M J 2012 Impact of Indian Ocean Dipole and El Niño/southern oscillation wind-forcing on the Wyrtki jets; J. Geophys. Res. - Oceans 117(C8) 1-11.

Han W 2005 Origins and dynamics of the 90-day and 30-60day variations in the equatorial Indian Ocean; J. Phys. Oceanogr. 35(5) 708-728.

Han W, Lawrence D M and Webster P J 2001 Dynamical response of equatorial Indian Ocean to intraseasonal winds: Zonal flow; Geophys. Res. Lett. 28(22) 4215-4218.

Han W, McCreary J P Jr, Anderson D and Mariano A J 1999 Dynamics of the eastern surface jets in the equatorial Indian Ocean; J. Phys. Oceanogr. 29(9) 2191-2209. 
Han W, McCreary J P, Masumoto Y, Vialard J and Duncan B 2011 Basin resonances in the equatorial Indian Ocean; J. Phys. Oceanogr. 41(6) 1252-1270.

Han W, Shinoda T, Fu L-L and McCreary J P 2006 Impact of atmospheric intraseasonal oscillations on the Indian Ocean dipole during the 1990s; J. Phys. Oceanogr. 36(4) 670-690.

Han W, Webster P, Lukas R, Hacker P and Hu A 2004 Impact of atmospheric intraseasonal variability in the Indian Ocean: Low-frequency rectification in equatorial surface current and transport; J. Phys. Oceanogr. 34(6) 1350-1372.

Iskandar I and McPhaden M J 2011 Dynamics of wind-forced intraseasonal zonal current variations in the equatorial Indian Ocean; J. Geophys. Res. - Oceans 116(C6) 1-16.

Joseph S, Wallcraft A J, Jensen T G, Ravichandran M, Shenoi S and Nayak S 2012 Weakening of spring Wyrtki jets in the Indian Ocean during 2006-2011; J. Geophys. Res. - Oceans 117(C4) 1-13.

Kalnay E et al. 1996 The NCEP/NCAR 40-year reanalysis project; Bull. Am. Meteor. Soc. 77(3) 437-471.

Krishnan R, Ayantika D, Kumar V and Pokhrel S 2011 The long-lived monsoon depressions of 2006 and their linkage with the Indian Ocean dipole; Int. J. Climatol. 31(9) 1334-1352.

Kumar B P, Vialard J, Lengaigne M, Murty V, McPhaden M J, Cronin M, Pinsard F and Reddy K G 2013 Tropflux wind stresses over the tropical oceans: Evaluation and comparison with other products; Clim. Dyn. 40(7-8) 2049-2071.

Large W G, McWilliams J C and Doney S C 1994 Oceanic vertical mixing: A review and a model with a nonlocal boundary layer parameterization; Rev. Geophys. 32(4) 363-403.

Lau K and Wu H 2010 Characteristics of precipitation, cloud, and latent heating associated with the Madden-Julian Oscillation; J. Climate 23(3) 504-518.

Lau W K-M and Waliser D E 2011 Intraseasonal variability in the atmosphere-ocean climate system; Springer Science \& Business Media, Chichester, UK.

Madden R A and Julian P R 1972 Description of global-scale circulation cells in the tropics with a 40-50 day period; J. Atmos. Sci. 29(6) 1109-1123.

Masumoto Y, Hase H, Kuroda Y, Matsuura H and Takeuchi K 2005 Intraseasonal variability in the upper layer currents observed in the eastern equatorial Indian Ocean; Geophys. Res. Lett. 32(2) 1-4.

McCreary J P Jr 1984 Equatorial beams; J. Mar. Res. 42(2) 395-430.

McCreary J P, Kundu P K and Molinari R L 1993 A numerical investigation of dynamics, thermodynamics and mixed-layer processes in the Indian Ocean; Prog. Oceanogr. 31(3) 181-244.

McPhaden M 1982 Variability in the central equatorial Indian Ocean. i. Ocean dynamics; J. Mar. Res. 40 157176.

McPhaden M J et al. 2009 RAMA: The research moored array for African-Asian-Australian monsoon analysis and prediction; Bull. Am. Meteorol. Soc. 90(4) 459480.

McPhaden M J, Wang Y and Ravichandran M 2015 Volume transports of the Wyrtki jets and their relationship to the
Indian Ocean dipole; J. Geophys. Res. - Oceans 120(8) $5302-5317$.

Miyama T, McCreary J P Jr, Sengupta D and Senan R 2006 Dynamics of biweekly oscillations in the equatorial Indian Ocean; J. Phys. Oceanogr. 36(5) 827-846.

Moum J N et al. 2014 Air-sea interactions from westerly wind bursts during the November 2011 MJO in the Indian Ocean; Bull. Am. Meteorol. Soc. 95(8) 1185-1199.

Murtugudde R and Busalacchi A J 1999 Interannual variability of the dynamics and thermodynamics of the tropical Indian Ocean; J. Climate 12(8) 2300-2326.

Murtugudde R, McCreary J P and Busalacchi A J 2000 Oceanic processes associated with anomalous events in the Indian Ocean with relevance to 1997-1998; J. Geophys. Res. - Oceans 105(C2) 3295-3306.

Nagura M and McPhaden M J 2008 The dynamics of zonal current variations in the central equatorial Indian Ocean; Geophys. Res. Lett. 35(23) 1-6.

Nagura M and McPhaden M J 2010a Dynamics of zonal current variations associated with the Indian Ocean dipole; J. Geophys. Res. - Oceans 115(C11) 1-12.

Nagura M and McPhaden M J 2010b Wyrtki jet dynamics: Seasonal variability; J. Geophys. Res. - Oceans 115(C7) $1-17$.

Nagura M and McPhaden M J 2012 The dynamics of winddriven intraseasonal variability in the equatorial Indian Ocean; J. Geophys. Res. - Oceans 117(C2) 1-16.

Nagura M and McPhaden M J 2014 Zonal momentum budget along the equator in the Indian Ocean from a highresolution ocean general circulation model; J. Geophys. Res. - Oceans 119(7) 4444-4461.

Papa F, Durand F, Rossow W B, Rahman A and Bala S K 2010 Satellite altimeter-derived monthly discharge of the Ganga-Brahmaputra River and its seasonal to interannual variations from 1993 to 2008; J. Geophys. Res. Oceans 115(C12) 1-19.

Popiński W, Kosek W, Schuh H and Schmidt M 2002 Comparison of two wavelet transform coherence and cross-covariance functions applied on polar motion and atmospheric excitation; Stud. Geophys. Geod. 46(3) 455468.

Rao R R, Molinari R L and Festa J F 1989 Evolution of the climatological near-surface thermal structure of the tropical Indian Ocean: 1. Description of mean monthly mixed layer depth, and sea surface temperature, surface current, and surface meteorological fields; J. Geophys. Res. - Oceans 94(C8) 10801-10815.

Reppin J, Schott F A, Fischer J and Quadfasel D 1999 Equatorial currents and transports in the upper central Indian Ocean: Annual cycle and interannual variability; J. Geophys. Res. - Oceans 104(C7) 15495-15514.

Schott F A and McCreary J P 2001 The monsoon circulation of the Indian Ocean; Prog. Oceanogr. 51(1) 1-123.

Senan R, Sengupta D and Goswami B 2003 Intraseasonal 'monsoon jets' in the equatorial Indian Ocean; Geophys. Res. Lett. 30(14) 1-4.

Sengupta D, Senan R, Goswami B and Vialard J 2007 Intraseasonal variability of equatorial Indian Ocean zonal currents; J. Climate 20(13) 3036-3055.

Shankar D, Remya R, Vinayachandran P, Chatterjee A and Behera A 2016 Inhibition of mixed-layer deepening 
during winter in the northeastern Arabian Sea by the West India Coastal current; Clim. Dyn. 47(3-4) 10491072.

Shinoda T, Han W, Jensen T G, Zamudio L, Joseph Metzger E and Lien R-C 2016 Impact of the Madden-Julian Oscillation on the Indonesian Throughflow in the Makassar Strait during the CINDY/DYNAMO field campaign; J. Climate 29(17) 6085-6108.

Shinoda T and Hendon H H 1998 Mixed layer modeling of intraseasonal variability in the tropical western Pacific and Indian Oceans; J. Climate 11(10) 2668-2685.

Sindhu B, Suresh I, Unnikrishnan A, Bhatkar N, Neetu S and Michael G 2007 Improved bathymetric datasets for the shallow water regions in the Indian Ocean; J. Earth Syst. Sci. 116(3) 261-274.

Sreenivas P, Chowdary J and Gnanaseelan C 2012 Impact of tropical cyclones on the intensity and phase propagation of fall wyrtki jets; Geophys. Res. Lett. 39(22) 1-6.

Vinayachandran P, Kurian J and Neema C 2007 Indian Ocean response to anomalous conditions in 2006; Geophys. Res. Lett. 34(15) 1-6.

Vinayachandran P, Saji N and Yamagata T 1999 Response of the equatorial Indian Ocean to an unusual wind event during 1994; Geophys. Res. Lett. 26(11) 1613-1616.

Vörösmarty C, Fekete B and Tucker B 1996 River discharge database, Version 1.0 (RivDis v1. 0), Vol. 0-6 (A contribution to IHP-v Theme: 1. TECH DOC HY series), UNESCO, Paris.

Waliser D, Stern W, Schubert S and Lau K 2003 Dynamic predictability of intraseasonal variability associated with the Asian summer monsoon; Quart. J. Roy. Meteor. Soc. 129(594) 2897-2925.

Wang H, Murtugudde R and Kumar A 2016 Evolution of Indian Ocean dipole and its forcing mechanisms in the absence of ENSO; Clim. Dyn. 47(7-8) 24812500 .

Wheeler M C and Hendon H H 2004 An all-season realtime multivariate MJO index: Development of an index for monitoring and prediction; Mon. Weather Rev. 132(8) 1917-1932.

Wu R and Kirtman B P 2004 Impacts of the Indian Ocean on the Indian summer monsoon-ENSO relationship; $J$. Climate 17(15) 3037-3054.

Wyrtki K 1973 An equatorial jet in the Indian Ocean; Sci. J. 181(4096) 262-264.

Yoshida K 1960 A theory of the Cromwell current (the equatorial undercurrent) and of the equatorial upwelling; J. Oceanogr. Soc. Japan 15(4) 159-170.

Yuan D and Han W 2006 Roles of equatorial waves and western boundary reflection in the seasonal circulation of the equatorial Indian Ocean; J. Phys. Oceanogr. 36(5) 930-944. 